\title{
Proposal of a Hybrid System for Solar and Photovoltaic for Lighting Low Cost
}

\author{
Ando Junior, O. H. ${ }^{1-2}$, Rosa, H. B. ${ }^{1}$, Spacek, A. D. ${ }^{1-2}$, Malfatti, C. F. ${ }^{2}$, Schaeffer, L. ${ }^{2}$ \\ ${ }^{1}$ Department of Electrical Engineering \\ SATC, Beneficent Association of Santa Catarina Coal Industry \\ Street Pascoal Meller, 73. Criciúma-Sc (Brazil) \\ Phone/Fax number: +55 48 3431-75.50, e-mail: oswaldo.junior@ satc.edu.br, henriqueborgesdarosa@yahoo.com.br, \\ anderson.spacek@satc.edu.br \\ ${ }^{2}$ School of Engineering \\ UFRGS, Federal University of Rio Grande do Sul \\ Av. Osvaldo Aranha, 103. Porto Alegre-Rs (Brazil) \\ Phone/Fax number: +55 51 3308-31.29, e-mail: celia.malfatti@ufrgs.br, schaefer@ufrgs.br
}

\begin{abstract}
This work consists of the study and development of a hybrid lighting system that uses Led as artificial light source and sunlight as a natural source. Starts with a survey of this technology being developed in the tubular lighting system as well as the search for its replacement by alternative materials as a way to fund the project, uniting quality and reduced cost. With the definition of constructive elements, proceeds to the beginning of project design and development of control to maintain brightness in the environment system. Using as guidance the Brazilian Standards, which govern the methods of measuring brightness, as well as the procedure for creating models scaled tools. Finally presents the tests and their results, demonstrating the possibility of developing a hybrid lighting system at low cost.
\end{abstract}

\section{Key words}

Low Cost, Natural Source, Lighting, Alternative Materials.

\section{Introduction}

Authors Electricity is considered basic to the development of society input, in addition to providing an improved quality of life, economic growth serves as parameter. The energy crisis is evidenced by the established limits of energy supply, which is predominantly based on nonrenewable sources [1].

In view of this, the energy issue has become vital for the entire planet, it is extremely important to find sustainable solutions that contribute to the energy matrix, prioritizing the replacement of nonrenewable other renewable energy sources [2].

The Brazilian energy potential from renewable resources is touted as one of the largest in the world, and these are scattered unevenly in various regions of the country. It was also observed that Brazil is in a favorable geographical position and making solar incidence around $5.5 \mathrm{kWh} / \mathrm{m}^{2}$ irradiance level much higher than countries like Germany, Spain and Portugal. [3], [4], [5], [6]

Therefore, we emphasize the feasibility of using this daylight system, since it is a clean, free and inexhaustible, which can be used directly for lighting energy environments. This fact, coupled with the use of recycled and reused materials in the construction of a project would result in an ecological, social and self-sustaining product (Green Energy). Consequently, the power sector would benefit from the reduction in consumption, and provide an increase in the availability of energy in the energy matrix.

\section{State of the Art}

Papers Capture technology, direction and conduct of sunlight are developed by specialized companies in the United States and Spain, which manufacture high quality products. In your case use highly efficient optical materials such as silver and aluminum, making it possible to "technology guide natural light" that can direct the sun's rays raised to the desired location with greater than $90 \%$ yields [7], [8].

The operation of this type of lighting system is composed of three fundamental elements, as can be seen in Figure 1 ; the dome is leased on the outside, has the function of receiving the sunlight and directs it into the tube. The driver duct, has highly reflective inner lining, he is responsible for transporting natural light reaching the dome and forward the same by reflection to the diffuser lens, this makes the dispersion of the received rays, improving distribution and illuminating the environment [7], [8].

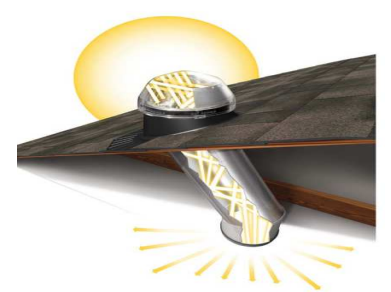

Fig. 1. Lighting System Tubular 


\section{Proposed System}

The tubular lighting system marketed focuses on the development of technology to achieve a high yield. This concern with efficiency, and a better finish on the product, refers the use of noble materials, raising the price of all the bit values feasible for small consumers. Given the high price and limited supply light to the environment only in the period when the sun is present, we sought an artificial solution to compensate for ambient lighting when there is no sunlight, or when it does not meet the needs lighting design stipulated by Norm NBR - 5413 [7], [8], [9].

Another important thing to note concerns the environmental impact generated by the product that during the life of the equipment can be considered negligible, but can be quite large for the future disposal.

Thus, the high cost of the product and the possible environmental impact generated at its disposal, along with the restriction of night lighting are motivators for the development of a system that uses alternative materials combined with elements of artificial lighting, high efficiency and low cost, becoming a commercially viable and socially oriented product.

\section{A. Dome}

Current lenses capture is developed in glass with heat treatment in the case of manufacturer Solar Espacio and acrylic with UV treatment by Solatube [7], [8].

The project proposes the use of tempered glass in the making of the dome as it is a material and abundant low cost marketing. There is also the fact that the glass having high refractive index, in addition, its mechanical and thermal characteristics were decisive for the choice of material, these characteristics can be analyzed in Table I [10]

Table I. - Data of Glass
\begin{tabular}{|l|c|c|}
\hline \multicolumn{1}{|c|}{ PROPERTIES } & UNIT & VALUE \\
\hline Refractive Index & & 1,51 \\
\hline Thermal Conductivity & $\mathrm{W} / \mathrm{mK}$ & 1,7 \\
\hline Transmission of solar radiation & $\%$ & 85 \\
\hline Flexural & $\mathrm{Kg}$ & 170 \\
\hline
\end{tabular}

The tempered glass as mentioned in Tab.1 shows good impact resistance as well as high refractive index, this phenomenon is of great importance to the work as it causes a shift in the direction of the rays as they pass from one medium to another, in other words, assists in targeting of direct sunlight into the pipe .

To mount the dome to capture, we used a piece of glass that has been divided and fitted in order to mount a prism, shown in Fig. 2.

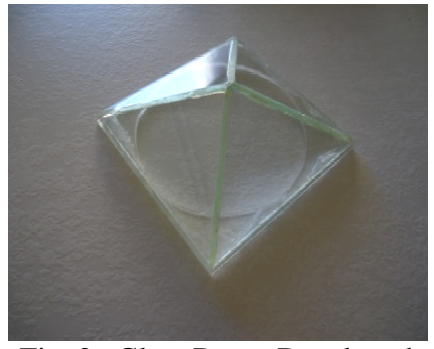

Fig. 2. Glass Dome Developed

\section{B. Duct}

In marketed designs, the material used in the reflective tube is aluminum, under justified to ensure that the mechanical strength of the product. To increase the reflective capacity of the pipe Solatube receives applying a Spectra Light Infinity ® film that provides $99.7 \%$ reflection, since the duct Espacio Solar receives on its inner face a superficial treatment of silver, which elevates levels yield to $98 \%$ [7], [8].

Aiming to reduce overall costs, we sought alternatives to the making of the prototype, and then it is suggested to replace the pipe material, currently aluminum, for Polyvinyl of Polyvinyl, better known as PVC. A very important fact is that in the case of substitution, it was necessary to evaluate an alternative to the reflective material that will be inside the tube, being chosen for this case to monomeric PVC film and automotive mirror film.

\section{PVC Pipe Proposed}

PVC replacement will be chosen for the common tube $100 \mathrm{~mm}$, this being easily found in building materials and $100 \%$ recyclable shops. The Table II presents the mechanical and constructional properties of PVC duct chosen; these data serve to benchmark with aluminum.

Table II - Comparison PVC and aluminum

\begin{tabular}{|l|c|c|c|}
\hline \multicolumn{1}{|c|}{ PROPERTIES } & UNIT & PVC & ALUMINUM \\
\hline Density & $\mathrm{mm}$ & 2 & 0,5 \\
\hline Maximum width & $\mathrm{mm}$ & 100 & 1250 \\
\hline Composition & {$[---]$} & PVC-U & $\mathrm{Al} 99,85$ \\
\hline Tensile strength & $\mathrm{MPa}$ & 20 a 50 & $140-180$ \\
\hline Melting point & ${ }^{\circ} \mathrm{C}$ & 180 & 660 \\
\hline
\end{tabular}

You can verify that the PVC pipes offer less mechanical strength comparing to aluminum. But it is understood that this issue does not preclude the replacement because the proposal to the applied load on the pipe is minimal, since the installation of the system will occur in roofs.

\section{Reflective Material Proposed}

In order to realize a low-cost design, we opted for alternative materials, such as the silver film called monomeric PVC film used in screen printing applications at the same time to compare it with other reflective material was applied inside the duct an automotive reflective film. The automotive film has features like, low thermal transmittance but reflective data are not mentioned. Have the monomeric PVC film manufacturer has no technical data to reflectivity, since its application is not focused on the purpose of this proposal, for both tests were performed to verify the efficiency of the films. The fig. 3 shows the film applied to the ducts [14].

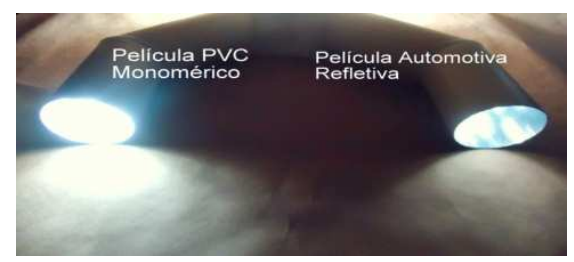

Fig. 3. Glass Dome Developed

In Figure 3 it can be seen visually and compare their reflective capabilities. It is possible to identify that the 
brightness of the coated PVC film monomeric tube is considerably greater than the luminosity arriving through the tube to the automotive reflective film; this indicates that the yield of monomeric PVC film is higher compared to insufilm.

\section{E. Diffuser}

For the diffuser lens, replacing the acrylic used for the Solatube and Solar Espacio, suggests the use of polycarbonate due to this being a material with good optical, mechanical properties and for this be found easily in the market. This is shown in Figure 4 and has excellent optical properties [15], [16].

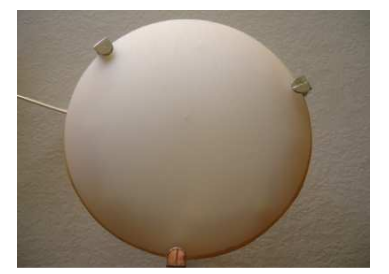

Fig. 4. Diffuser Lens

The diffuser lens is the component of the project leased inside the room, she is responsible for receiving the sun's rays and light produced by the LED 's and spread them in the desired area, this was still shaped to be coupled to the lamp and reflective duct.

\section{$\boldsymbol{E}$. Mounting the alternative system of daylight}

For mounting of daylight system, we used made the dome, reflective and duct diffuser lens, these were coupled as shown in Fig 5.

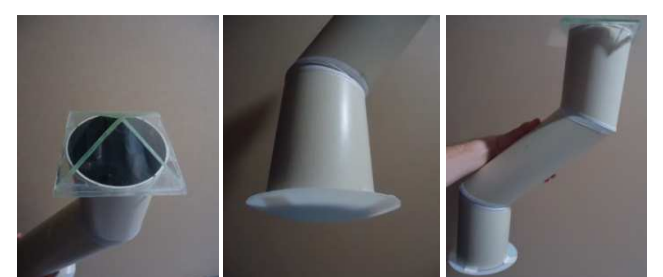

Fig. 5. Tubular System Developed Lighting

In Figure 5 the alternative system is presented, showing the location of the dome at one end of the reflective duct, the site of attachment of diffusing lens and finally the full prototype. A test to prove the ability to conduct light system was performed. For this was the prototype led to a place with free sky, with one end of the duct in direct contact with sunlight, and the other leased within a fenced enclosure as Fig. 6.

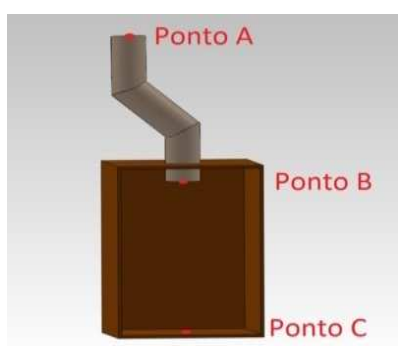

Fig. 6. Layout Test

As seen in Figure 6, the tube has developed an angle to show that the incident light is totally internally reflected, this angle is necessary so there is no direct sunlight on the underside of the duct. The red dots represent the locations where measurements of brightness were made.

First we measured the brightness at point $\mathrm{C}$ with the box closed, to prove that the light would come only by reflective duct, the result was 0 lux. Since then, there have been tests with coated pipelines; the results are presented in Table III.

Table III - Data of Glass

\begin{tabular}{|l|c|c|}
\hline $\begin{array}{l}\text { MEASUREMENT } \\
\text { SITE }\end{array}$ & $\begin{array}{l}\text { MONOMERIC PVC } \\
\text { FILM }\end{array}$ & $\begin{array}{l}\text { AUTOMOTIVE } \\
\text { FILM }\end{array}$ \\
\hline Point A & 54000 lux & 54000 lux \\
\hline Point B & 22000 lux & 14500 lux \\
\hline Efficiency & $40,74 \%$ & $26,85 \%$ \\
\hline
\end{tabular}

With values, it is possible to obtain efficiency of the tubes, and this is the ratio of the brightness value of the input tube and output value. The test monomeric PVC film obtained an efficiency of $40.74 \%$, as with automotive film efficiency was $26.85 \%$. With this check was decided to develop the system monomeric PVC film, since she was the one with higher yield.

\section{$\boldsymbol{F}$. Led luminary}

As a way to supplement the ambient light, a provider of artificial light system was developed. It was chosen for the power LED $3 \mathrm{~W}$, on the grounds that being a lowenergy consumption and high performance lighting. Among the main features that point lighting are: long service life, low operating voltage and the fact that his firing be very fast.

For the prototype, we used six LED `s $3 \mathrm{~W}, 18 \mathrm{~W}$ total power of the light, this will be the maximum power consumed by the system. For the lamp were attached to the tubular ergonomic lighting system form, this had its base developed ring-shaped, so that it could be fitted to the duct and stay hidden by diffusing lens, besides providing sufficient space for the attachment of LED`s . In developed luminary, LED`s were fixed on an aluminum plate, with the aim of engaging the one end of the reflective duct, besides working as a sink of heat generated by the LED`s, which contributes to the quality of emitted light and the life of the LEDs. With the production of LED luminary, the hybrid lighting system is complete, having an alternative system of natural lighting and an artificial light source. Figure 7 shows the LED lamp and developed hybrid system.

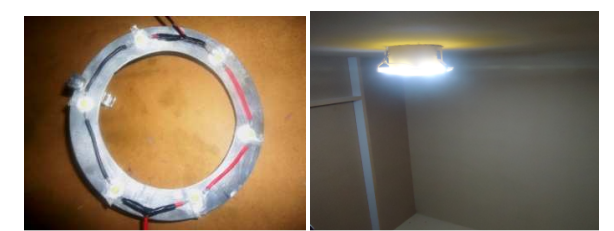

Fig. 7. Led Light and Hybrid System Developed

The Figure 7 shows the design of the luminary, with the location where the LED's are attached and form of electrical connection of the artificial system. This consists of two series connections of three LED's, which are connected in parallel to each other. This setting causes the lamp to work with a maximum current of $1400 \mathrm{~mA}$, adjusted to a voltage of $10.8 \mathrm{~V}$ which is exerted by the control system. 
In the developed hybrid luminary, the lighting in the environment comes through artificial and natural environments, both light beams are homogenized in diffuser lens, can still realize that the environment has good distribution and good level of luminance.

\section{System Validation}

To validate the results of the prototype, we developed a system of validation in accordance with current standards.

\section{A. Environment Modeling Scaled}

The development of the model was carried out under the light of ISO 15215-4 that directs the manufacture of smallscale modeling. For this purpose, was used as real environment a small meeting room of the Faculty Satc of $3 \times 3 \times 3 \mathrm{~m}$. The modeling was done on a scale of $3: 1$, in other words, the environment in reduced scale has $1 \mathrm{x} 1 \mathrm{x} 1 \mathrm{~m} .8$ show the recreation of the environment [17].

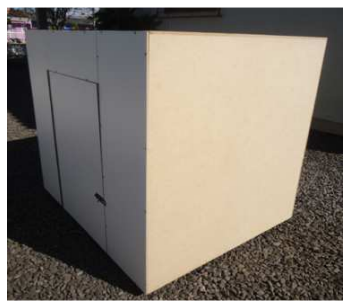

Fig. 8. Modeling of Living Scale 3:1

The room keeps recreated the physical characteristics of the room scaled matrix, and this totally sealed so that no light from the corners of the wall.

\section{B. Determination of the Level of Luminance}

To determine the luminance NBR 5413-1992, which provides the levels of illuminati an environment for each activity group, is utilized. Because the environment is being illuminated a meeting of an educational institution, the standard recommends the values of Table IV [18].

Table IV - Level of Luminance in the Environment

\begin{tabular}{|l|c|}
\hline TYPE ENVIRONMENT & LUX \\
\hline \multicolumn{2}{|c|}{ Schools } \\
\hline Meeting room & $150-200-300$ \\
\hline
\end{tabular}

The values of standard ranged from 150 to 300 lux, depending on the characteristics of the task and the observer. For the project will be used as the parameter value of 200 lux, with the index referenced by the regulatory norm.

\section{Measurement Methodology}

To conduct measurements were lighting a local, you should follow the procedures of ISO 5382 1985. Defined as the place to be lit environment is a regular fixture $1 \mathrm{~m}^{2}$ and has developed only one central point lighting. Was used as the measurement model Figure 9, shows that the places where they should make the collection of measured values [19].

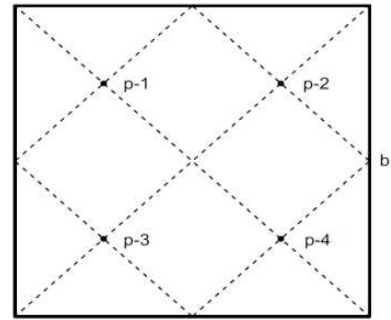

Fig. 9. Locations for Measurement of Luminosity

For the measurements, the standard that governs the measurement with the light meter should be held to $80 \mathrm{~cm}$ from the floor. As this work using a reduction factor of $3: 1$, measurements were made on a backing of $26.5 \mathrm{~cm}$, thereby simulating the height of a work surface. Figure 10 shows the locations where measurements with the sensor were performed [19].

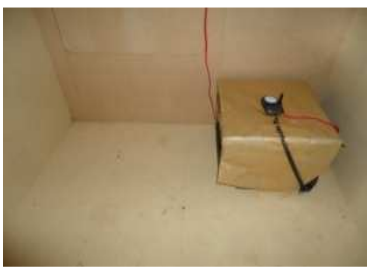

Fig. 10. Locations of Measurements in Reduced Environment

To validate the measurements in each position of the light meter was recorded a value to later do the arithmetic average of the ambient light, so the procedure is valid because all the conditions of measurements required by the standards are met in the project.

\section{Monitoring and control brightness}

For system monitoring and control of hybrid luminary used a integrated Arduino platform, LDR sensors to collect data on the luminosity, and the LED light source to act as the system. Even as a contribution to the project, developed a small electronic circuit that is responsible for carrying out the commands of the lighting system.

For monitoring the light was coupled LDR in the center of the light tube, to verify the amount of light that the sun provides the hybrid system. The control system and the position of LRD are shown in Figure 11.

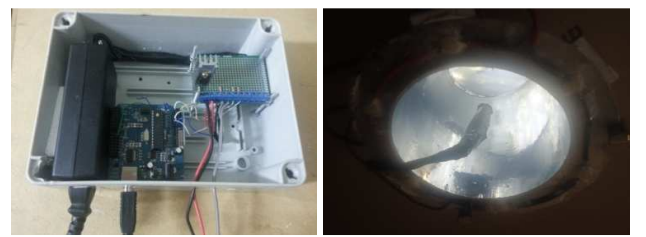

Fig. 11. System Control and Positioning of the LDR

In Figure 11 we observe the electronic system developed, with the power board with their source connections, sensors and LED luminary. Reportedly this also the LDR and its placement site. This sensor is coupled to the analog input Arduino, the reading is performed in the form of voltage, being a 10-bit input, or received by Arduino values are between from 0 to 1023 .

To control the lighting system has been used in open loop, and the system only monitors the amount of light that the duct receives the sun. For firing the LED `s used the PWM output, and this is an 8-bit output. As a source of supply for $12 \mathrm{~V}$ power system was used, the Arduino controls the tension in the range of 0 to $12 \mathrm{~V}$. 
The purpose of this work is the use of a modeling program cascade; this was determined by the values obtained and the analysis of the sensor fixed inside the duct and the reflective luminance values provided by LED's lamp. With these it was possible to find the relationship between reading the LDR and the amount of natural light that came to the environment. How to read the LDR has high variation, reading groups were created, and each of these groups was given a value of PWM output.

With the aid of this programming system, you can control the brightness within the simulated environment, because the sensor will send a value of reading and the program will evaluate the range in which the reading is and will subsequently send a value of PWM output to control brightness of the LED luminary. Doing it this way that artificial lighting is only triggered whenever necessary, aiming to save the maximum power consumption.

\section{Tests Performed}

For the tests we used all measurement procedures cited in this study, measurements of light in the environment were governed by NBR 5382 , and the level of illuminance within the room on a small scale was guided by NBR 5413 , with this definition were started the tests .

Initial tests were performed to adjust the parameters of the control system, the procedure took place with modeling positioned in a location free from shadows, and brightness values were measured inside the room with the light meter . To perform the graphical analysis, using four LDR ' $\mathrm{s}$ coupled with the light meter inside the small room, these sensors were fixed at the points indicated by the standard and calibrated by the values in light meter and its average was presented on the Arduino .

]Measurements were performed during the whole day, being initiated at sunrise and closed the ending of the day, samples were collected every second, containing the brightness values within the environment and the values measured in LDR duct, the amount of light reflected within the tubular system. The data collected is possible to analyze the lighting capacity of the natural system, the control system working and check the period that the system is more efficient, as well as to measure the energy consumption of the system.

\section{Analysis of Results}

For initial analysis of data relating to natural lighting system were collected in order to measure its operation and its ability to illuminate the environment, Figure 12 shows the reduced luminance within the room.

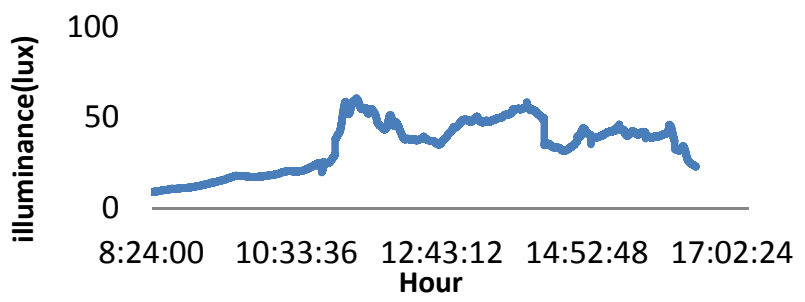

Fig. 12. Illuminance Provided by the Natural System

As a way to evaluate the project, measurements were performed at times with greater intensity of solar lighting.
Data collection was made during 8am, and it can be seen that the system of tubular lighting acts as the sun is present. Peak occurred on that day light where the values reached 60 lux, with these data is possible to analyze the variation in brightness occurs due to the timings solar position and also natural interference during the day. For this test, has been running the artificial lighting system, together with the control developed, because this way the hybrid system can be analyzed. Figure 13 shows the data collected for one hour on a sunny day.

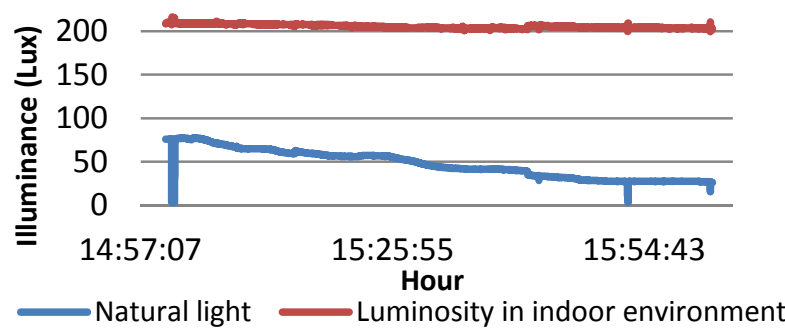

Fig. 13. Measurement of Luminosity in the Environment

It is observed in Figure 13 that the light transmitted by the natural system, has high value in the first instants of measurement, reaching contribute $80 \mathrm{lux}$, it is also observed that the brightness in indoor environment is constant during the test, even with the insertion of interference to the system, this fact is due to the brightness control used, it causes the LED lamp is lit with greater or lesser extent, depending on the solar incidence. For the design has been determined that 200 lux is the minimum acceptable value, and this variation should not be longer than $7 \%$, that is, the luminance level should not exceed 214 lux which was successful in the experiment. For better evaluation of the project collections for a period of consecutive 9a.m., where we sought to analyze the developed hybrid system were performed. The data collected are presented in Figure 14 and Figure 15.

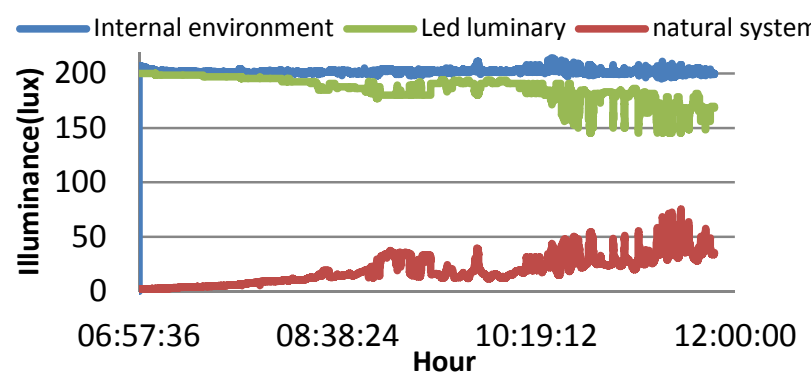

Fig. 14. Measurement of Luminosity in the Environment

The data of Figure 14 were collected during one morning, from 7 am to 12p.m. In this time interval data from the sensors to capture light reflective duct and positioned within the simulated environment, as well as the light intensity emitted by the LED luminaire sensors were received.

We notice that the lines for the brightness of the natural system and the brightness of the LED luminaire, present with opposite results, this fact is the differential of the proposal as the moment that the system of natural lighting provides a higher level of illuminance, LED luminaire has his firing with less intensity. The sun of illumination the result is provided in lux within the small room. 
It may be noted that the illuminance provided by the natural system, high peaks and dips occur are those times when the sun comes out the masking of clouds and the sky is open, or vice versa. This fact has made the system of monitoring and control required was enough, and that was important to check its operation and evidence of their efficacy. Figure 15 shows the complement of the test.

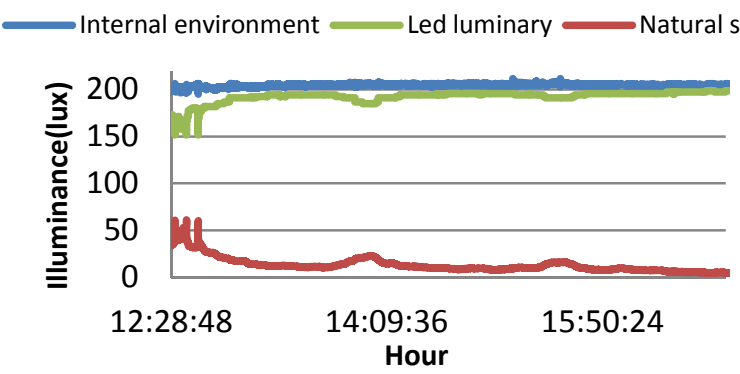

Fig. 15. Measurement of Luminosity Evening Period

With the analysis of Figure 14 and 15, it can be observed that even in times of low light intensity, the system provided good daylighting illuminance level of the hybrid set, and that the LED luminaire acted to complement the level ambient lighting, thus keeping the level of predetermined luminance.

With the data collected, it was possible to analyze the average income for each component of the hybrid lighting system proposed. And for a day with average luminance and high incidence of clouds, the system of natural lighting provided 20 lux on average, with peaks of 75 lux, which corresponds to $38 \%$ of the brightness within the boardroom . The rest of light in the environment was under responsibility of the Led luminaire, which provided about 180 lux in the middle of the day, this value corresponds to an average consumption of $6.2 \mathrm{~W}$. To compare the consumption of the hybrid luminaire proposal made to swap the Led lighting, for conventional bulbs, an incandescent $60 \mathrm{~W}$ bulb yielded 65 lux to the system, as a compact fluorescent lamp 20W provided 208 lux inside the environment; these values prove the efficiency of the project developed, and the savings achieved.

\section{Conclusion}

This paper presented a proposal to develop a hybrid lighting system, where your goal was able to capture and drive quality sunlight, using this recyclable and reusable materials. Just as the creation of an artificial lighting system, to meet the illuminance in an environment when no solar irradiation.

To validate the results, we developed a small-scale prototype of a real environment. This has been successfully implemented, providing conditions for verification of results, in addition, all measurements were performed according to current regulations, giving the results normalized values.

The system developed daylighting obtained satisfactory results, showing approximate illuminance level of 80 lux for a simulated environment and to the measurements prescribed by rule; this value corresponds to $38 \%$ of lighting required for the chosen environment.

The making of the LED luminaire prototype autonomy granted to the ambient lighting in all periods of the day, and this element supplied all the needs of the luminance project, furthermore, its energy consumption occurred in a low, below the expected, where at worst it consumes $7.5 \mathrm{~W}$.

The application of the hybrid system to control lighting system was possible to analyze the functioning of the proposal, as this suited the LED lighting with natural light, this fact rendered a good level of electrical energy to the prototype economy, and for the day with a high level of illuminance, their consumption will be approximately $4.5 \mathrm{~W}$.

Thus it is concluded that the proposed initial goals were achieved, where the daylighting system showed satisfactory results, and the control of luminance remained the minimum level required by the rules, moreover, cost effective development took place very below the system currently marketed, with proposal also enables the luminance at night, further elevating its advantages.

\section{References}

[1] S. Leonardo, Análise de Desempenho de um Gerador Termoelétrico Baseado no Efeito Seebeck, Dissertação Universidade de Taubaté, Taubaté, (2010), pp. 45.

[2] A, Joaquim, Reaproveitamento de Calor para Geração de Energia Elétrica no Automóvel.. Dissertação - Universidade Do Minho, Braga, (2011), pp. 155.

[3] L, Ana Luiza, A. Lizandra, Aproveitamento Energético do Biogás em Aterros Sanitários, BNDES Setorial, Rio de Janeiro (2008), pp. 59-100.

[4] C. Sergio, P. Enio, Atlas de Irradiação Solar do Brasil. Inmet/Labsolar, Brasília (1998).

[5] C. Luciana. A Eletricidade Subiu no Telhado. Unesp Ciência, São Paulo (2012), pp. 18-25.

[6] MAPA DA ENERGIA SOLAR . Available in: < http://www.electronica-pt.com/index.php/content/ view/272/203/>. Acess: 15 jun. 2013.

[7] ESPACIO SOLAR, Catalogo Espacio Solar iluminação natural Available in: <http://espaciosolar.com/fichas.htm>. Acess: 6 Jan. 2013.

[8] SOLATUBE, Catálogo Solatube iluminação natural - Available in: 〈http://www.solatube.com/es/productcatalog .htm>. Acess: 5 Jan. 2013.

[9] TUBYSOL, Catálogo Tubysol iluminação solar - Available in: <http://www.tubysol.es/en/daylighting-pipe.html>. Acess: 6 Jan. 2013.

[10] C. Willian, R. David. Ciência e Engenharia de Materiais: uma introdução, LTC, Rio de Janeiro (2009).

[11] Garante Vidros, Catálogo técnico - Available in: < http://www.garantevidros.com.br/downloads/cat_tec_garante.pdf >. Acess: 01 Mar. 2013.

[12] C. Christiano, Metalurgia das ligas de alumínio e tratamentos no metal líquido, Senai, Itaúna (2001).

[13] Amanco, Manual Técnico Amanco Colefort Tubos - Available in: $<$ http://www.amanco.com.br/web/image/texto/Manual_ Tecnico_Colefort-Rev_dez.08.pdf>. Acess: 06 Abr. 2013.

[14] Insulfilm, Catálogo de insulfilm arquitetônico - Available in: < http://www.insulfilmarquitetonico.com.br/>. Acess: 21 Fev. 2013.

[15] Inberg, J. P. F.; Gaymans, R. J. - Polymer, 43. Espanha: Elsevier, 2002.

[16] J. Wiley, Encyclopedia of polymer science and engineering. Interscience, New York (1968), v. 11, pp. 648-718.

[17] Associação Brasileira De Normas Técnicas (Org.). NBR 15215-4, Abnt, Rio de Janeiro (2004).

[18] Associação Brasileira De Normas Técnicas (Org.). NBR 5413, Abnt, Rio de Janeiro (1992).

[19] Associação Brasileira De Normas Técnicas (Org.). NBR 5382, Abnt, Rio de Janeiro (1985). 